\title{
Trajectory Planning of a Constrained Flexible Manipulator
}

\author{
Atef A. Ata E Habib Johar
}

\section{Introduction}

Many of today's flexible robots are required to perform tasks that can be considered as constrained motions. A robot is considered to be in constrained maneuvering when its end-effector contacts and/or interacts with the environment as the robot moves. These applications include grinding, deburring, cutting, polishing, and the list continues. For the last two decades many researchers have investigated the constrained motion problem through different techniques such as hybrid position/force control (Raibert, M. \& Craig, J., 1981 and Shutter et al., 1996), force control (Su, et al., 1990), nonlinear modified CorlessLeitman controller (Hu, F. \& Ulsoy, G., 1994), two-time scale force position control (Rocco, P. \& Book, W., 1996), multi-variable controller (Shi, et al., 1990), parallel force and position control (Siciliano \& Villani, L.,2000), and multi-time-scale fuzzy logic controller (Lin, J., 2003). Luca et al. (Luca, D. \& Giovanni, G., 2001) introduced rest-to-rest motion of a twolink robot with a flexible forearm. The basic idea is to design a set of two outputs with respect to which the system has no zero dynamics. Ata and Habib have investigated the open loop performance of a constrained flexible manipulator in contact with a rotary surface (Ata, A. \& Habib, J., 2004) and arbitrary shaped fixed surfaces (Ata, A. \& Habib, J., 2004). The effect of the contact force on the required joint torques has been simulated for different contact surfaces. Despite the voluminous research done, the study of dynamics and control of the constrained motion of the flexible manipulators remains open for further investigations.

The present study aims at investigating the dynamic performance of a constrained rigid/flexible manipulator. The Cartesian path of the end-effector is to be converted into joint trajectories at intermediate points (knots). The trajectory segments between knots are then interpolated by cubic-splines to ensure the smoothness of the trajectory for each joint. To avoid separation between the end-effector and the constraint surface and to minimize the contact surface as well, these knots are chosen at the contact surface itself. Simulation results have been carried out for three contact surfaces.

\section{Dynamic Modeling}

Consider the two-link planar manipulator shown in Figure (1). The first link is rigid while the second link is flexible and carries a tip mass m3. This tip mass always moves in contact with a constrained surface. The mass density of the flexible link is $\rho_{2}$ and EulerBernoulli's beam theory is employed to describe the flexural motion of the flexible link. The manipulator moves in the horizontal plane so that the effect of gravity is not 
considered. The flexible link is described by the Virtual Link Coordinates System (VLCS) in which the deformation is measured relative to the link that joins the end-points and the angle $\theta$ is measured with respect to the horizontal axis (Benati, M. \& Morro, A., 1994).

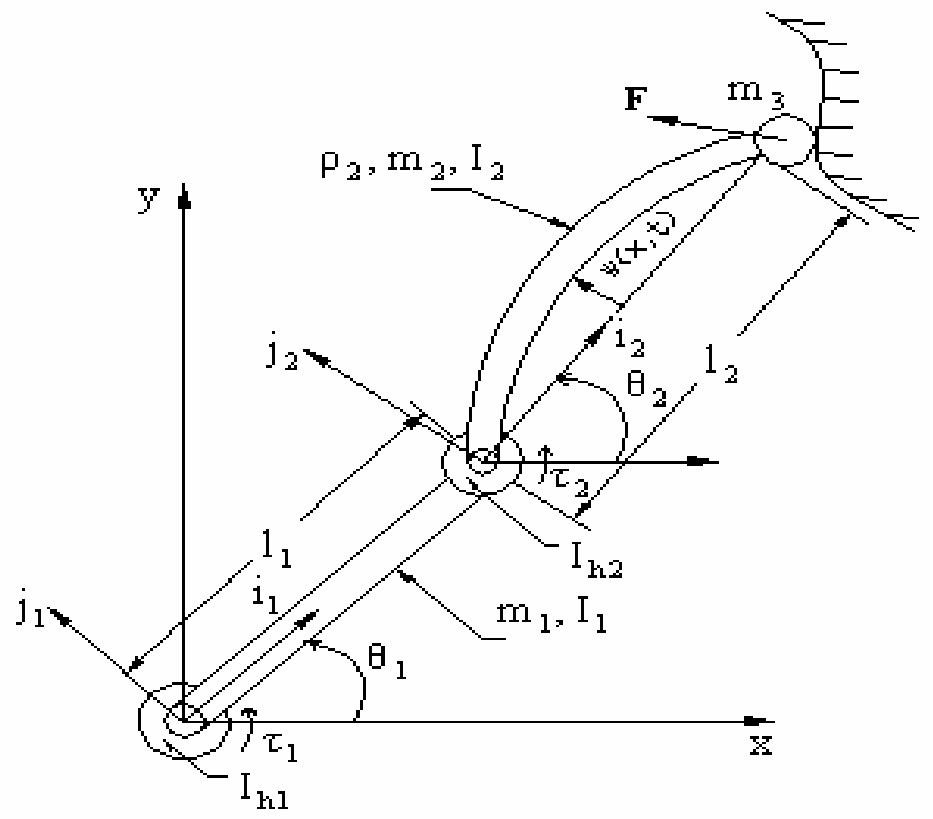

Figure 1. A two link rigid-flexible manipulator with tip mass

In general, the dynamic equation of motion for a rigid-flexible robot can be written as:

$$
\tau=\mathrm{M}(\theta) \ddot{\theta}+\mathrm{V}(\theta, \dot{\theta})+\tau_{\mathrm{r}}
$$

where $\Theta$ is $n x 1$ vector of joint positions; $\Theta$ is $n x 1$ vector of joint velocities; $\Theta$ is $n x 1$ vector of joint accelerations; $M(\Theta)$ is the $n x n$ inertia matrix; $V(\Theta, \Theta)$ is the $n x 1$ Coriolis and centripetal terms of the manipulator; $\tau$ is the $n x 1$ vector of joint torques, $n$ is the number of degrees of freedom. Based on the dynamical model of an open chain multi-link flexible manipulator using the extended Hamilton's principle [Ata, A. \& Habib, J., 2004 and Benati, M. \& Morro, A., 1994], the elements of the inertia and Coriolis matrices of the rigid/flexible manipulator considered here are shown on the appendix .

$\tau_{r}$ is the $n x 1$ interaction joint torques due to the force exerted at the end-effector and is given by:

$$
\tau_{\mathrm{r}}=\mathrm{J}^{\mathrm{T}} \mathrm{F}=\mathrm{J}^{\mathrm{T}}\left[\begin{array}{l}
\mathrm{F}_{\mathrm{x}} \\
\mathrm{F}_{\mathrm{y}}
\end{array}\right]
$$

where $J^{T}$ is the transpose Jacobian of the system.

$F_{x}$ and $F_{y}$ represent the applied forces by the end-effector on the constrained surface and it includes two parts. The first component is due to the difference between the proposed coordinates of the end-effector in free motion state and the corresponding point in the contact surface and can be modeled as mass-spring system (Raibert, M. \& Craig, J., 1981). The second part arises from the inertia of the tip mass while maneuvering. Then the components of the contact force can be given as: 


$$
\begin{aligned}
& F_{x}=K_{s}\left(r_{x}-l_{1} \cos \theta_{1}-l_{2} \cos \theta_{2}\right)+m_{3}\left(l_{1} \ddot{\theta}_{1} \sin \theta_{1}\right. \\
& \left.+l_{1} \dot{\theta}_{1}^{2} \cos \theta_{1}+l_{2} \ddot{\theta}_{2} \sin \theta_{2}+l_{2} \dot{\theta}_{2}^{2} \cos \theta_{2}\right) \\
& F_{y}=K_{s}\left(r_{y}-l_{1} \sin \theta_{1}-l_{2} \sin \theta_{2}\right)+m_{3}\left(l_{1} \dot{\theta}_{1}^{2} \sin \theta_{1}\right. \\
& \left.-l_{1} \ddot{\theta}_{1} \cos \theta_{1}+l_{2} \dot{\theta}_{2}^{2} \sin \theta_{2}-l_{2} \ddot{\theta}_{2} \cos \theta_{2}\right)
\end{aligned}
$$

Where $K_{S}$ is the spring stiffness $(\mathrm{N} / \mathrm{m}), r_{x}$, and $r_{y}$ are the coordinates of the contact point. For the second link, the equation due to the flexibility effect can be written as:

$$
\rho_{2}\left\{w \dot{\theta}_{2}^{2}-\ddot{w}-x \ddot{\theta}_{2}-l_{1}\left[\dot{\theta}_{1}^{2} \sin \left(\theta_{2}-\theta_{1}\right)+\ddot{\theta}_{1} \cos \left(\theta_{2}-\theta_{1}\right)\right]\right\}-E_{2} I_{2} w^{\prime \prime \prime \prime}=0
$$

where $E_{2} I_{2}$ is the flexural stiffness of the flexible link. Equation (4) describes the vibration of the flexible link subject to four boundary conditions:

$$
\begin{gathered}
w(0, t)=0 \\
w\left(l_{2}, t\right)=0 \\
w^{\prime \prime}(0, t)=-\frac{\tau_{2}(t)}{E_{2} I_{2}} \\
w^{\prime \prime}\left(1_{2}, t\right)=0
\end{gathered}
$$

\section{Inverse Dynamics Analysis}

By introducing a new variable $y(x, t)$ which represents the total deflection of the flexible link as:

$$
y(x, t)=w(x, t)+x \theta_{2}(t)
$$

By ignoring the first nonlinear term of equation (4), since its effect is only obvious at very high speed, then equation (4) can be written in terms of $y(x, t)$ as:

$$
\rho_{2}\left\{-\ddot{y}-l_{1}\left[\dot{\theta}_{1}^{2} \sin \left(\theta_{2}-\theta_{1}\right)+\ddot{\theta}_{1} \cos \left(\theta_{2}-\theta_{1}\right)\right]\right\}-E_{2} I_{2} y^{\prime \prime \prime}=0
$$

The modified boundary conditions are:

$$
\begin{aligned}
y(0, t) & =0 \\
y\left(l_{2}, t\right) & =1_{2} \theta_{2}(t) \\
y^{\prime \prime}(0, t) & =-\frac{\tau_{2}(t)}{E_{2} I_{2}} \\
y^{\prime \prime}\left(1_{2}, t\right) & =0
\end{aligned}
$$

Solving equation (7) analytically subject to the time-dependent inhomogeneous boundary conditions ( $8 \mathrm{~b}$ and $\mathrm{c}$ ) is quite a difficult task since the flexible torque $\tau_{2}(t)$ that should be obtained is already included in the boundary conditions for the total deflection $y(x, t)$. To avoid this difficulty, $\tau_{2}(t)$ is assumed as the rigid torque without any elastic effect. The boundary condition (8c) can then be evaluated and equations (7) and (6) can be solved to get $w(x, t)$. Finally upon substitution into equation (1) one can get the flexible torque of the 
second link. Using the assumed mode method, the solution for $y(x, t)$ can be assumed in the form (Meirovitch, L., 1967 and Low, K., 1989):

$$
\left.\mathrm{y}_{\mathrm{n}}(\mathrm{x}, \mathrm{t})=\underset{\mathrm{n}=1}{\dagger} \mathrm{t}_{\mathrm{n}}(\mathrm{x}) \zeta_{\mathrm{n}}(\mathrm{t})\right]+\mathrm{g}(\mathrm{x}) \mathrm{e}(\mathrm{t})+\mathrm{h}(\mathrm{x}) \mathrm{f}(\mathrm{t})
$$

where:

$$
\begin{aligned}
& e(t)=l_{2} \theta_{2}(t) \\
& f(t)=-\frac{\tau_{2}(t)}{E_{2} I_{2}}
\end{aligned}
$$

$g(x)$ and $h(x)$ are functions of the spatial coordinate alone to satisfy the homogeneous boundary conditions for $v_{n}(x)$ and they are given by:

$$
\begin{gathered}
\mathrm{g}(\mathrm{x})=\mathrm{x} \\
\mathrm{h}(\mathrm{x})=-\frac{1}{3} \mathrm{l}_{2} \mathrm{x}+\frac{1}{2} \mathrm{x}^{2}-\frac{1}{6 \mathrm{l}_{2}} \mathrm{x}^{3}
\end{gathered}
$$

and $\zeta_{n}(t)$ is the time function. The subscript $\mathrm{n}$ represents the number of modes taking into considerations. In this study, five modes of vibration of the flexible link have been taken into consideration. The corresponding eigenvalue problem for equation (7) can be written:

$$
\mathrm{k}_{2} \frac{\mathrm{d}^{4} \mathrm{v}(\mathrm{x})}{\mathrm{dx}^{4}}+\omega^{2} \rho \mathrm{v}(\mathrm{x})=0
$$

Then $v_{n}(x)$ can be obtained using modal analysis in the form (Clough, R. \& Penzien, J., 1993):

$$
\mathrm{v}_{\mathrm{n}}(\mathrm{x})=\sqrt{\frac{2}{\rho \mathrm{l}_{2}}} \sin \frac{\mathrm{n} \pi}{\mathrm{l}_{2}} \mathrm{x}, \mathrm{n}=1,2,3 \ldots
$$

The last two nonlinear terms inside the parentheses in equation (6) can be regarded as distributed excitation force with unit density. This effect can be compensated for the time function as (Meirovitch, L., 1967 and Low, K., 1989):

$$
\zeta_{n}(t)=\frac{1}{\omega_{n}} \int_{0}^{t} N_{n} \tau \sin (t-\tau) d \tau
$$

The convolution integral in equation (13) can be evaluated using Duhamel integral method (Clough, R. \& Penzien, J., 1993). Then, the rigid and flexible torques incorporated with vibration effects can be obtained from equations (1).

\section{Model Verification}

To verify the proposed dynamical model a simulation of the joint torques through the solution of the inverse dynamics problem has been carried out for different values of the hub to beam inertia ratio (IR). The inertia ratio is defined as the percentage of the 
actuator's inertia to the link inertia that, i. e., inertia ratio $=($ Hub inertia $/$ Link inertia $)$. The joint profiles are assumed as a sine rest-to-rest maneuver for both links as:

$$
\theta_{\mathrm{n}}=\frac{\theta_{\mathrm{nd}}}{\mathrm{T}}\left(\mathrm{t}-\frac{\mathrm{T}}{2 \pi} \sin \left(\frac{2 \pi \mathrm{T}}{\mathrm{T}}\right)\right)
$$

where $\Theta_{n d}=1 \mathrm{rad}$ is the desired final angle and $\mathrm{T}=5 \mathrm{sec}$. is the duration time. The system parameters used in this study (Luca, D. \& Giovanni, G., 2001) are summarized in Table (1).

\begin{tabular}{|l|l|l|}
\hline & Rigid & Flexible \\
\hline Length $(\mathrm{m})$ & $\mathrm{l}_{1}=0.5$ & $\mathrm{l}_{2}=0.75$ \\
\hline $\begin{array}{l}\text { Mass density } \\
(\mathrm{kg} / \mathrm{m})\end{array}$ & & $\rho_{2}=0.5$ \\
\hline Mass $(\mathrm{kg})$ & $\mathrm{m}_{1}=0.5$ & $\mathrm{~m}_{2}=\mathrm{L}_{2}{ }^{*} \rho_{2}$ \\
\hline Inertia $\left(\mathrm{kgm}^{2}\right)$ & $\mathrm{I}_{1}=0.0834$ & $\mathrm{I}_{2}=\left(1_{2}{ }^{3 *} \rho_{2} / 3\right)$ \\
\hline Hub inertia $\left(\mathrm{kgm}^{2}\right)$ & $10 \mathrm{I}_{1}$ & $10 \mathrm{I}_{2}$ \\
\hline $\begin{array}{l}\text { Flexural rigidity } \\
\left(\mathrm{Nm}^{2}\right)\end{array}$ & & $\mathrm{E}_{2} \mathrm{I}_{2}=2.4507$ \\
\hline Tip mass & $0.15 \mathrm{Kg}$ & \\
\hline
\end{tabular}

Table 1. System parameters

Four different inertia ratios have been used to simulate and compare the joint torque profiles as shown in Figure 2(a-d) for unconstrained motion. The end-effector is maneuvering freely in space and thus, no contact force is included in joint torque simulation.

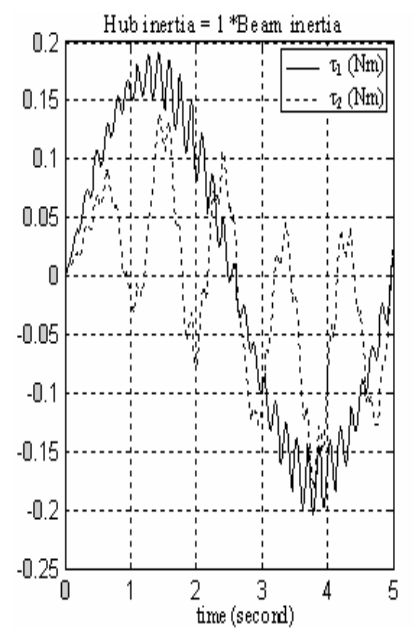

a) $\mathrm{IR}=1.0$

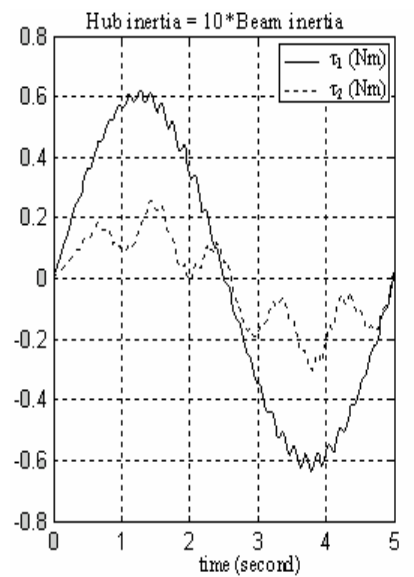

c) $\mathrm{IR}=10.0$

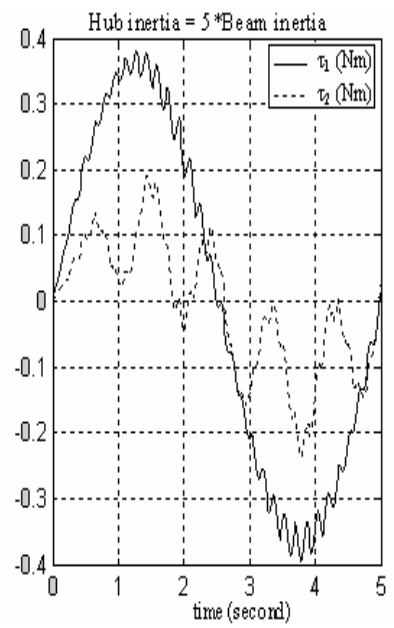

b) $\mathrm{IR}=5.0$

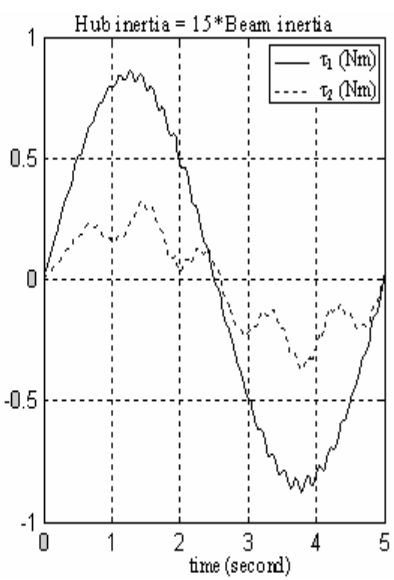

d) $\mathrm{IR}=15.0$

Figure 2(a-d). Joint torque profiles for different inertia ratios 
It is clear from Figure 2(a-d) that fluctuations arise in joint torques due to the vibrations of flexible link while the manipulator is maneuvering.

As the inertia ratio increases, the magnitude of the joint torques increases and the amplitudes of fluctuations decrease. It should be noticed that the amplitudes of fluctuations in joint torques resulting from inertia ratio of 10 have significantly diminished as compared to those of inertia ratio of 1 and 5 . This implies that vibration effects on joint torques can be damped to certain extent with a good selection of inertia ratio. The situation is even better for an inertia ratio of 15 where the fluctuations are very much significantly reduced but the price is a bigger actuator size. However, since we desire to design light weight manipulator, inertia ratio of 10 is more preferable to that of 15 . This conforms with the stability analysis of stable and asymptotically stable flexible manipulator (Ata, et al., 1996).

\section{Cubic-Spline Trajectory Interpolations}

Generally, the trajectory of the robot arm is specified in the task space, while the robot is controlled in the joint space. Using inverse kinematics and Jacobian, the desired path and velocity can be converted to joint trajectories and velocities.

Among the interpolation path planning methods, the piecewise cubic and B-spline polynomial joint paths are often adopted due to their easy and fast mathematic manipulation.

Unfortunately, a B-spline does not go through the knots of the path though they are suitable for on-line computation. In case of cubic-spline trajectory interpolation, joint angles are well calculated beforehand for certain points on the surface as such the end effector strictly remains in contact with the surface at those particular points while maneuvering (Cao, et al., 1994).

Then, the obtained joint angles through the solution of the inverse kinematics problem are interpolated using cubic-spline for entire surface such that the end effector closely maneuvers along the surface. To study the variation of the contact force and its effect on the joint torques, three different compliant surfaces are applied here: circular, inclined, and vertical. For each surface, the force exerted at the end-effector and the required joint torque for both links are plotted in Figures 3,4, and 5 respectively.

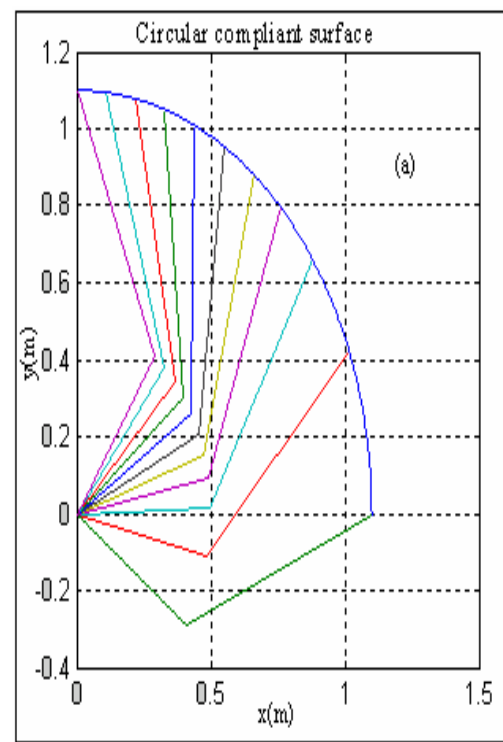

(a)

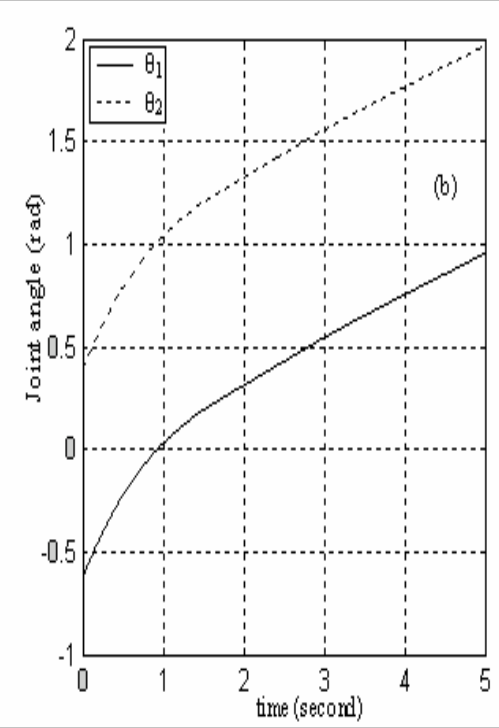

(b) 


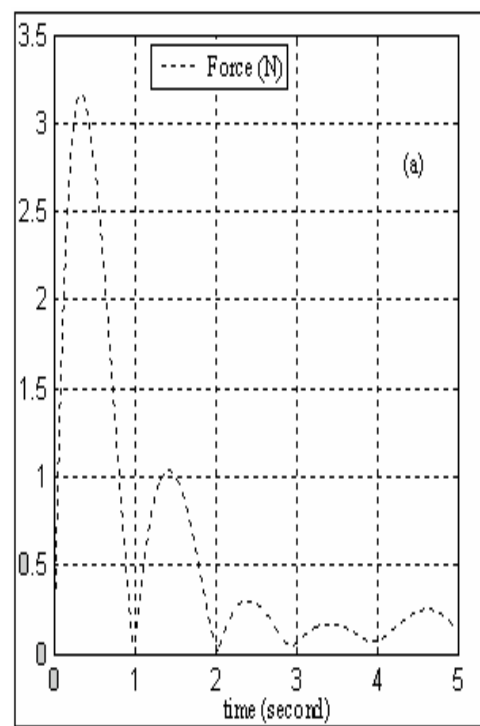

(c)

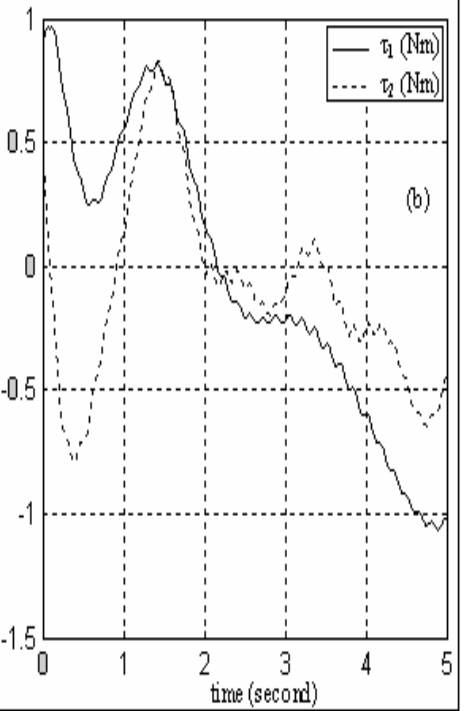

(d)

Figure 3. Circular surface: (a) End-effector trajectory, (b) Joint angles (c) Force distribution (d) Joint torques profiles

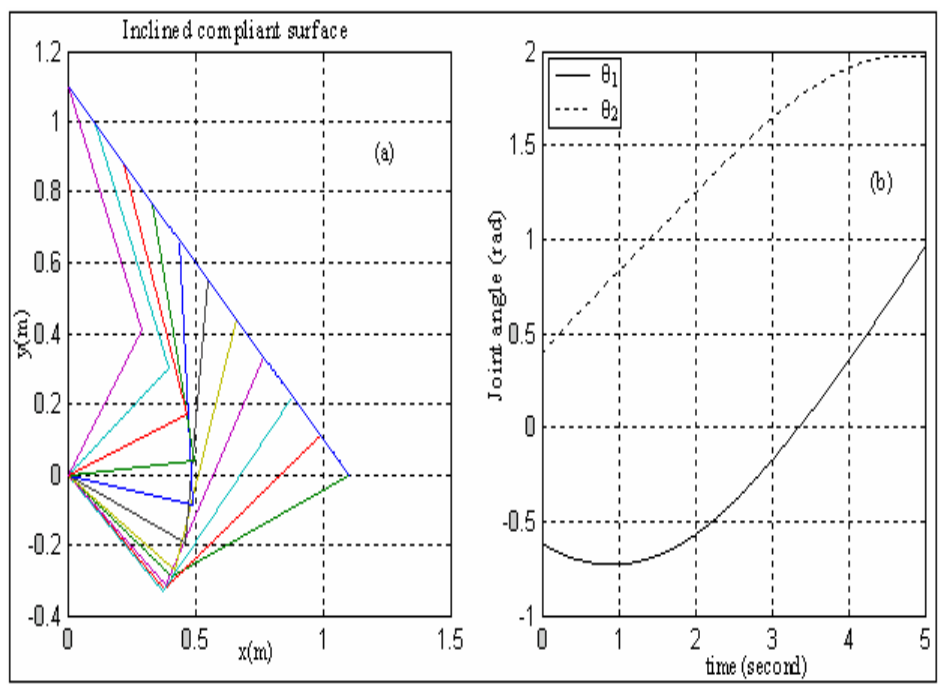

(a)

(b)

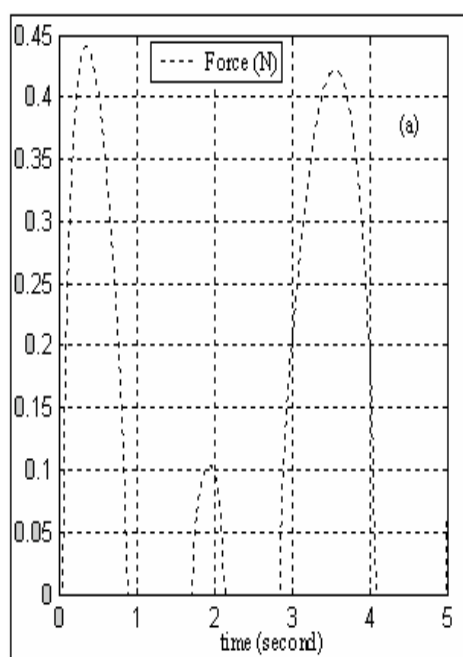

(c)

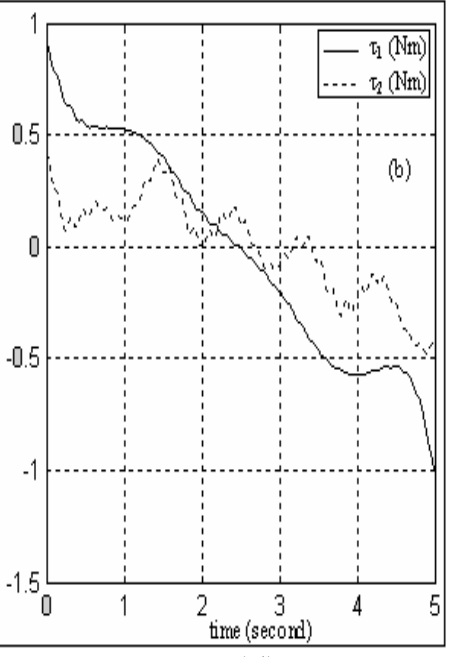

(d)

Figure 4. Inclined Surface: (a) End-effector trajectory, (b) Joint angles (c) Force distribution (d) Joint torques profiles 


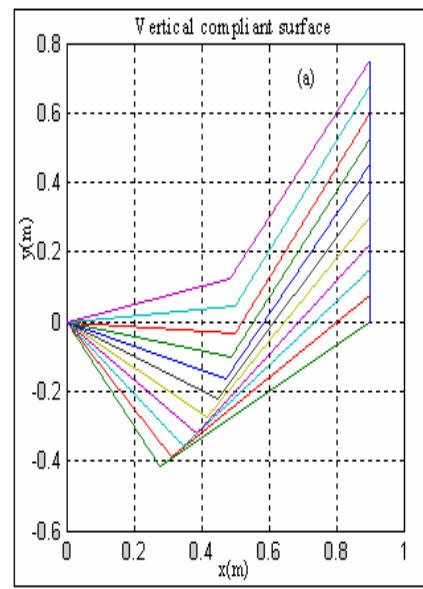

(a)

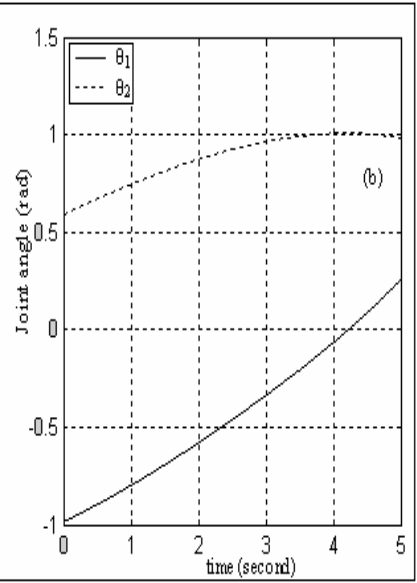

(b)

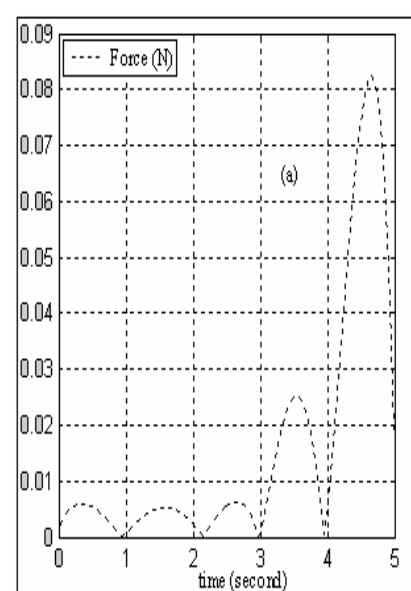

(c)

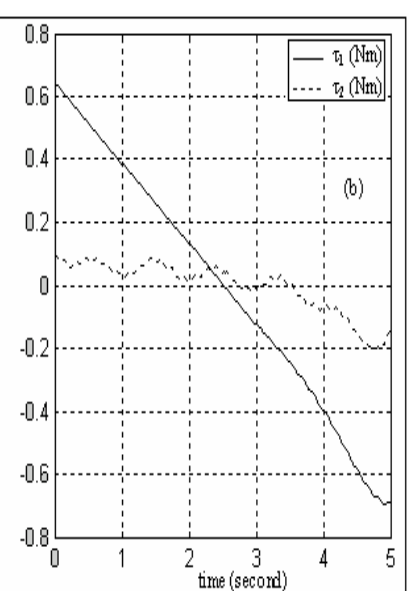

(d)

Figure 5. Vertical surface: (a) End-effector trajectory, (b) Joint angles (c) Force distribution (d) Joint torques profiles

Simulation of force distribution in Figures 3(c), 4(c) and 5(c) verifies that designing the joint trajectories based on cubic-splines ensures that the end effector closely maneuvers along the desired trajectory. However, in the case of circular contact surface, the initial force distribution in Figure 3(a) is relatively high within the time interval of 0 to 1 second and then gradually reduces as the end effector moves along the surface. This force is expected to be small since the end-effector is controlled to pass closely to the constraint surface. This implies that the cubic-spline interpolation technique may have a good command on the end-effector to maneuver closely along the entire contact surface only for certain shapes of surface. Perhaps for complicated shapes of contact surface, the cubicspline interpolation technique may not work well to compel the end effector to maneuver closely along the entire region of the contact surface.

The simulation of the joint torque profiles in Figures 3(b), 4(b) and 5(b) shows that irregular fluctuations can appear in the joint torque profiles due to the effect of cubicspline interpolation.

\section{Conclusions}

Constrained motion of a planar rigid-flexible manipulator is considered in this study. a dynamic model with zero tip deformation constraint of constrained rigid-flexible 
manipulator moving in horizontal plane is derived. A systematic approach of analytic solution to the fourth order differential equation with time dependent, nonhomogeneous boundary conditions including the nonlinear terms is presented to compute the elastic deflection $\mathrm{w}(\mathrm{x}, \mathrm{t})$ of the flexible link while maneuvering. The joint motion profiles have been designed based on the cubic-splines interpolation to ensure that the end-effector will move along the constrained surface without separation. The proper hub to beam inertia ratio of 10 has been selected based on a comparison study

\section{Appendix}

Equations of motion

$$
\begin{gathered}
\mathrm{M}_{11}=\left(\mathrm{I}_{1}+\mathrm{I}_{\mathrm{h} 1}+\mathrm{m}_{2} \mathrm{l}_{1}^{2}+\mathrm{m}_{3} 1_{1}^{2}\right) \\
M_{12}=\left(m_{2} l_{1} \bar{x}_{2}+m_{3} l_{1} l_{2}\right) \cos \left(\theta_{2}-\theta_{1}\right) \\
-\int_{0}^{l_{2}} \rho l_{1} w \sin \left(\Theta_{2}-\Theta_{1}\right) d x \\
M_{22}=\left(I_{2}+I_{h 2}+I_{3}+m_{3} l_{2}^{2}\right)+\int_{0}^{l_{2}} \rho w^{2} d x \\
v_{11}=-\left(m_{2} l_{1} \bar{x}_{2}+m_{3} l_{1} l_{2}\right) \dot{\theta}_{2}^{2} \sin \left(\theta_{2}-\theta_{1}\right)+\int_{0}^{l_{2}} \rho_{2} l_{1}\left[\left(\ddot{w}-w \dot{\theta}_{2}^{2}\right) \cos \left(\theta_{2}-\theta_{1}\right)-\left(2 \dot{w} \dot{\theta}_{2}\right) \sin \left(\theta_{2}-\theta_{1}\right)\right] d x \\
v_{21}=\left(m_{2} l_{1} \bar{x}_{2}+m_{3} l_{1} l_{2}\right) \dot{\theta}_{1}^{2} \sin \left(\theta_{2}-\theta_{1}\right)+\int_{0}^{l_{2}} \rho_{2}\left\{-2 w \dot{w} \dot{\theta}_{2}+x \ddot{w}+l_{1} w \dot{\theta}_{1}^{2} \cos \left(\theta_{2}-\theta_{1}\right)\right\} d x
\end{gathered}
$$

where $m_{2} \bar{x}_{2}=\int_{0}^{l_{2}} \rho_{2} x d x$ and $I_{n}$ and $I_{h n}$ are the inertia of the links and actuators respectively.

$$
\mathbf{J}^{\mathrm{T}}=\left(\begin{array}{ll}
-1_{1} \sin \theta_{1}-1_{2} \sin \theta_{2} & 1_{1} \cos \theta_{1}+1_{2} \cos \theta_{2} \\
-1_{2} \sin \theta_{2} & 1_{2} \cos \theta_{2}
\end{array}\right)
$$

\section{References}

Atef A. Ata \& Habib Johar (2004) “ Dynamic Analysis of a Rigid-Flexible Manipulator constrained by Arbitrary Shaped Surfaces", International Journal of Modelling and Simulation, To appear soon.

Atef A. Ata \& Habib Johar (2004) "Dynamic simulation of task constrained of a rigidflexible manipulator", International Journal of Advanced Robotic Systems, Vol. 1, No. 2, June 2004, pp. 61-66.

Atef, A. Ata , Salwa M. Elkhoga, Mohamed A. Shalaby, \& Shihab S. Asfour (1996) “ Causal inverse dynamics of a flexible hub- arm system through Liapunov second method" Robotica Vol. 14, pp 381-389.

Benati, M. \& Morro, A. (1994). Formulation of equations of motion for a chain of flexible links using Hamilton's principle. ASME J. Dynamic System, Measurement and Control , 116, pp. 81-88.

Cao, B., Dodds, G. I., \& Irwin, G. W.(1994). Time Optimal and Smooth Constrained Path Planning for Robot Manipulators. Proceeding of IEEE International Conference on Robotics and Automation, pp. 1853-1858. 
Clough, R.W. \& Penzien, J. (1993). Dynamics of Structures, McGraw-Hill, Inc.,.

Hu, F. L. \& Ulsoy, G. (1994). Force and motion control of a constrained flexible robot arm. ASME, J. Dynamic System, Measurement and Control, 116, pp. 336-343.

Lin, J. (2003). Hierarchical fuzzy logic controller for a flexible link robot arm performing constrained motion task, IEE Proceedings: Control Theory and Applications, Vol. 150, No. 4, , pp. 355-364.

Low, K. H.(1989). Solution schemes for the system equations of flexible robots. J. Robotic Systems, 6, pp. $383-405$.

Luca, D. A. \& Giovanni, D. G. (2001). Rest-to-Rest motion of a two-link robot with a flexible forearm. IEEE/ASME Int. Conf. on Advanced Intelligent Mechatronics, pp. 929-935.

Meriovitch, L. (1967). Analytical Methods in Vibrations. The Macmillan Co., New York.

Raibert, M. H. \& Craig J. J. (1981). Hybrid position / force control of manipulator, ASME J. of Dyanmics Systems, Measurement and Control, 102, pp. 126-133.

Rocco P. P \& Book, W. J. (1996). Modeling for two-time scale force/position control of flexible arm. IEEE Proc. International conference on Robotics and Automation, pp. 1941-1946.

Schutter , J. D., Torfs, D. \& Bruyninckx , H. (1996). Robot force control with an actively damped flexible end-effector. J. Robotics and Autonomous System, 19, pp. 205-214.

Shi, Z. X., Fung, E. H. K., and Li, Y. C. (1999). Dynamic modeling of a rigid-flexible manipulator for constrained motion task control. J. Applied Mathematical Modeling 23, pp. 509-529.

Siciliano \& Villani, L. (2000). Parallel force and position control of flexible manipulators. IEE Proc-Control Theory Appl. 147, pp. 605 -612.

$\mathrm{Su}, \mathrm{H}$. J., Choi, B. O. \& Krishnamurty , K. (1990). Force control of high-speed, lightweight robotic manipulator. Mathl. Comput. Modeling 14, pp. $474-479$. 


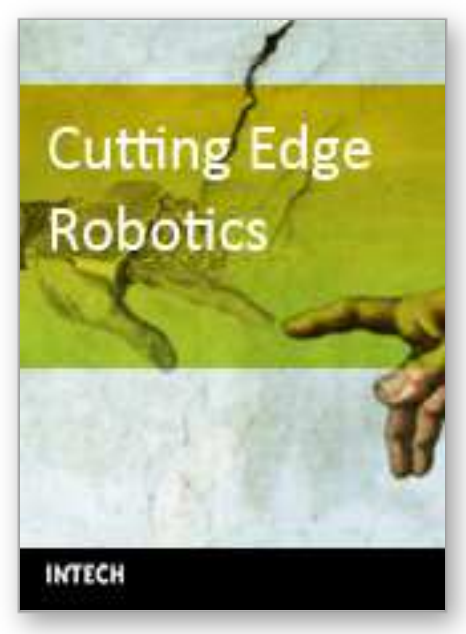

\section{Cutting Edge Robotics}

Edited by Vedran Kordic, Aleksandar Lazinica and Munir Merdan

ISBN 3-86611-038-3

Hard cover, 784 pages

Publisher Pro Literatur Verlag, Germany

Published online 01, July, 2005

Published in print edition July, 2005

This book is the result of inspirations and contributions from many researchers worldwide. It presents a collection of wide range research results of robotics scientific community. Various aspects of current research in robotics area are explored and discussed. The book begins with researches in robot modelling \& design, in which different approaches in kinematical, dynamical and other design issues of mobile robots are discussed. Second chapter deals with various sensor systems, but the major part of the chapter is devoted to robotic vision systems. Chapter III is devoted to robot navigation and presents different navigation architectures. The chapter IV is devoted to research on adaptive and learning systems in mobile robots area. The chapter V speaks about different application areas of multi-robot systems. Other emerging field is discussed in chapter VI - the human- robot interaction. Chapter VII gives a great tutorial on legged robot systems and one research overview on design of a humanoid robot. The different examples of service robots are showed in chapter VIII. Chapter IX is oriented to industrial robots, i.e. robot manipulators. Different mechatronic systems oriented on robotics are explored in the last chapter of the book.

\section{How to reference}

In order to correctly reference this scholarly work, feel free to copy and paste the following:

Atef A. Ata and Habib Johar (2005). Trajectory Planning of a Constrained Flexible Manipulator, Cutting Edge Robotics, Vedran Kordic, Aleksandar Lazinica and Munir Merdan (Ed.), ISBN: 3-86611-038-3, InTech, Available from:

http://www.intechopen.com/books/cutting_edge_robotics/trajectory_planning_of_a_constrained_flexible_manip ulator

\section{INTECH}

open science | open minds

\author{
InTech Europe \\ University Campus STeP Ri \\ Slavka Krautzeka 83/A \\ 51000 Rijeka, Croatia \\ Phone: +385 (51) 770447 \\ Fax: +385 (51) 686166 \\ www.intechopen.com
}

\author{
InTech China \\ Unit 405, Office Block, Hotel Equatorial Shanghai \\ No.65, Yan An Road (West), Shanghai, 200040, China \\ 中国上海市延安西路65号上海国际贵都大饭店办公楼 405 单元 \\ Phone: +86-21-62489820 \\ Fax: +86-21-62489821
}


(C) 2005 The Author(s). Licensee IntechOpen. This chapter is distributed under the terms of the Creative Commons Attribution-NonCommercial-ShareAlike-3.0 License, which permits use, distribution and reproduction for non-commercial purposes, provided the original is properly cited and derivative works building on this content are distributed under the same license. 